\title{
The Effect of Smartphones Use on Altering the Level of Attention and Learning Styles among Undergraduate Nursing Students in Kenya
}

\author{
David Kaniaru ${ }^{*}$, Anne Karani ${ }^{2}$, Mirie Waithera ${ }^{2}$ \\ ${ }^{1}$ Masinde Muliro University of Science and Technology, School of Nursing Midwifery and Paramedics \\ ${ }^{2}$ Nursing and Nursing Education, School of Nursing Science University of Nairobi
}

DOI: $10.36348 /$ sjnhc.2020.v03i10.001

| Received: 19.09 .2020 | Accepted: 27.09 .2020 | Published: 03.10 .2020

*Corresponding author: David Kaniaru

\section{Abstract}

Background: The use of cell phones can harm nursing students' academic performance. As such, reliance on the device for everyday activities has increased. Consequently, "nomophobia", defined as the fear of being without one's smartphone, has emerged as a new phobia among the users. Aim: This study was aimed at identifying the effects that long-term use of smartphone has among students cause on their level of attention and learning styles. Methodology: A quasi-experimental study was carried out among nursing students in two public universities located in western Kenya. The sample size comprised of 811 third- and fourth-years nursing students with a control group $(\mathrm{n}=349,43 . \%)$ and an experimental group $(n=462,57 \%)$. The experimental group left their cell phones, in sound or vibration mode, as they normally kept them, on a table located in the corner of the classroom. Data were analysed using SPSS v.25, and data presented using graphs and tables. The data was reliable at alpha .824 and without outliers. Results: More female 54.87\% than male was evidenced by the responses. Both groups showed higher-than-average levels of nomophobia at the beginning of the class. As for problematic smartphone use and attention, it was found that there were statistically significant differences in both cases $(\mathrm{U}=1355.500, \mathrm{Z}=-2.830, \mathrm{P}=.005 ; \mathrm{U}=1449.000, \mathrm{Z}=-2.363, \mathrm{P}=.018$, respectively), and the experimental group had higher average scores, as well as in those related to knowledge. Testing of the hypothesis was done and the null hypothesis was rejected $(\mathrm{X} 2=19.609, P>0.001)$. Conclusion: A relationship has been found between nomophobia and problematic smartphone use. Students who do not have access to their cell phones during class perceive more problematic cell phone usage, in addition to paying closer attention during class. Recommendation: Because of this, it is important to an alternative way of reducing the nomophobia in order to enhance attention and learning styles among students. Future studies are recommended on lecturers not only the students the medical students but also in other departments of the university and expand to other universities across the country.

Keywords: Attention, smartphone, Learning style, Nomophobia, Nursing students.

Copyright @ 2020: This is an open-access article distributed under the terms of the Creative Commons Attribution license which permits unrestricted use, distribution, and reproduction in any medium for non-commercial use (NonCommercial, or CC-BY-NC) provided the original author and source are credited.

\section{INTRODUCTION}

In the last few years, cell phones have become an essential part of our lives. Because of their many features, such as their small size, which makes them easy to carry around, as well as the ease with which we can access information or contact virtually anyone at the touch of a button, they are ubiquitous nowadays in both social and professional settings [1]. Nevertheless, cell phones have been shown to be addictive, leading to problematic use of such devices [2]. This problematic use has been associated with negative behaviours and emotions among users. Among these negative effects are the habit of compulsive checking ${ }^{3}$ and an increased tolerance, meaning constantly having to use these devices for longer periods of time in order to feel satisfied[4], as well as depression, and anxiety when away from the phone [5, 6]. Another problem associated with the problematic use of cell phones is nomophobia. Nomophobia is defined as an uncontrollable fear of feeling disconnected when one is unable to access information or contact others without a cell phone [7]. Other authors have found that nomophobia generates anxiety, anguish, and physical and psychological stress $[3,6,8]$. In addition, separation from one's phone can actually cause a decrease in executive performance, including changes in inhibitory control and working memory capacity [9].

On the other hand, cell phones are being used more and more among nursing students in educational 
and clinical practicum settings $[10,11]$. There are several studies that have explored the advantages of using cell phones in educational and clinical settings $[12,13]$. Regarding the benefits of cell phones, nursing students highlight that they can access educational material online, improve their knowledge, and use their time more effectively [13-15] as well as calculate medicine dosages [16]. More specifically, nursing students report that, not only do cell phones act as a means of support in making clinical decisions, but they also increase confidence, decrease anxiety, and reduce stress $[13,17,18]$.

However, there are very few studies that have explored problematic use of cell phones and nomophobia in nursing students. Nursing students generally show high levels of nomophobia [19, 20]. Along the same lines, a study carried out on 755 nursing students showed a positive correlation between the level of nomophobia, problematic cell phone use, social appearance anxiety, and social media use [19]. Furthermore, there have been studies exploring the risk of using cell phones during clinical practicum. More specifically, cell phone use and nomophobia have been associated with distraction among nursing students during clinical practicum $[21,22]$. This improper use of cell phones can put the safety of the patient at risk [21].

In the academic field, various studies have demonstrated the negative impact of excessive cell phone use on academic performance [23, 24], although there is only one study that relates nomophobia to attention in class among university students. This study, carried out on 160 psychology students, shows that the participants who had a higher degree of nomophobia paid less attention as the class went on [25].

Despite the previously mentioned studies, none have explored the influence of nomophobia or problematic cell phone use on nursing students and how these phenomena can interfere with their academic environment, affecting both attention and academic performance. Thus, the purpose of this study was to determine the effect problematic cell phone use and nomophobia have on learning and attention in nursing students.

\section{METHODS}

\section{Study Design}

A quasi-experimental study was performed.

The participants were randomly assigned to an experimental group (EG) and a control group (CG).

\section{Participants}

A total of 124 students studying for a nursing degree took part in the study (Figure 1). Inclusion criteria were (1) being 18 years of age or older and (2) being enrolled in the subject "Adult Nursing I" in the second year of the nursing degree program. Exclusion criterion was being a foreign exchange student.
Students were randomly assigned to each group. The students were drawn from two public universities in Kenya.

\section{INSTRUMENTS}

\section{To collect data, the following questionnaires were used}

The Nomophobia Questionnaire (NMP-Q) was developed and validated by Yildirim and Correia. ${ }^{7}$ The questionnaire consists of 20 questions, divided into four domains: not being able to access information (questions 1-4), giving up convenience (questions 5-9), not being able to communicate (questions 10-15), and losing connectedness (questions 16-20). These responses are scored on a Likert-type scale that range from 1 to 7, with 1 being "totally disagree" and 7 being "totally agree." The total scores were calculated by adding up all the values of each of the responses, giving a range of scores between 20 and 140 points. The highest scores correspond to more severe nomophobia. The reliability, which verifies the internal consistency of the scale, has a Cronbach's $\alpha$ value of .945 . For this study, we used the version of the scale that was adapted and validated to the Spanish context with a sample of nursing students. This version of the NMP-Q obtained a Cronbach's $\alpha$ value of .927[26].

The problematic use of cell phones was evaluated using the Mobile Phone Problematic Use Scale, developed and validated by Bianchi and Phillips [27], with a Cronbach's $\alpha$ value of .93. For this study, we used the version adapted and validated in an adult Spanish population, which has a high reliability, with a Cronbach's $\alpha$ value of .939[28]. The questionnaire consists of 26 items with a range of possible responses on a Likert-type scale, with 1 meaning "never" and 5 meaning "always." The questions are divided into four main factors. The first factor, "Abuse and Excessive Phone Use," is made up of 11 questions focused on recurring thoughts and problematic cell phone use (questions 14-20), alterations in mood due to lack of access to data (question 22), alterations in daily life (6, 17, 21, and 24), discomfort (question 18), and personal awareness of abuse or environmental warnings (questions 4, 15, and 23). The second factor, "Loss of Control," is made up of eight questions, encompassing problems derived from the progressive abandonment of personal affairs (questions 3, 5, and 8), lack of control that leads to using the cell phone more than expected (questions 9, 11, and 19), and as a way to compensate for dysphoric moods (questions 2 and 10). The third factor, "Social Context-Induced Craving," made up of six questions, refers to the personal perception of negative effects that come with the inaccessibility to cell phones and subjects' need to be connected in certain social settings $(7,12,13,16,25$, and 26). The fourth factor, "Tolerance," is made up of one question and is associated with the tendency to increase cell phone use (question 1). The total score is obtained by adding up the scores of each question, giving a range of possible 
scores from 26 to 130. Higher scores show greater levels of problematic cell phone use.

The Mindful Attention Awareness Scale evaluates one's attention/awareness in a given moment of daily life. The questionnaire was developed and validated by Brown and Ryan [29], obtaining high reliability scores (Cronbach's $\alpha=.87$ ). This study used the version adapted and validated to the Spanish adult population, also showing good reliability (Cronbach's $\alpha$ $=.89$ )[30]. The questionnaire comprised the factor, "Attention/Awareness," made up of 15 questions with a range of possible responses on a Likert-type scale from 1, "almost always," to 6, "almost never." The total score is obtained by adding up the scores of each question, giving a range of possible scores from 15 to 90 . Higher scores show higher levels of attention and awareness.

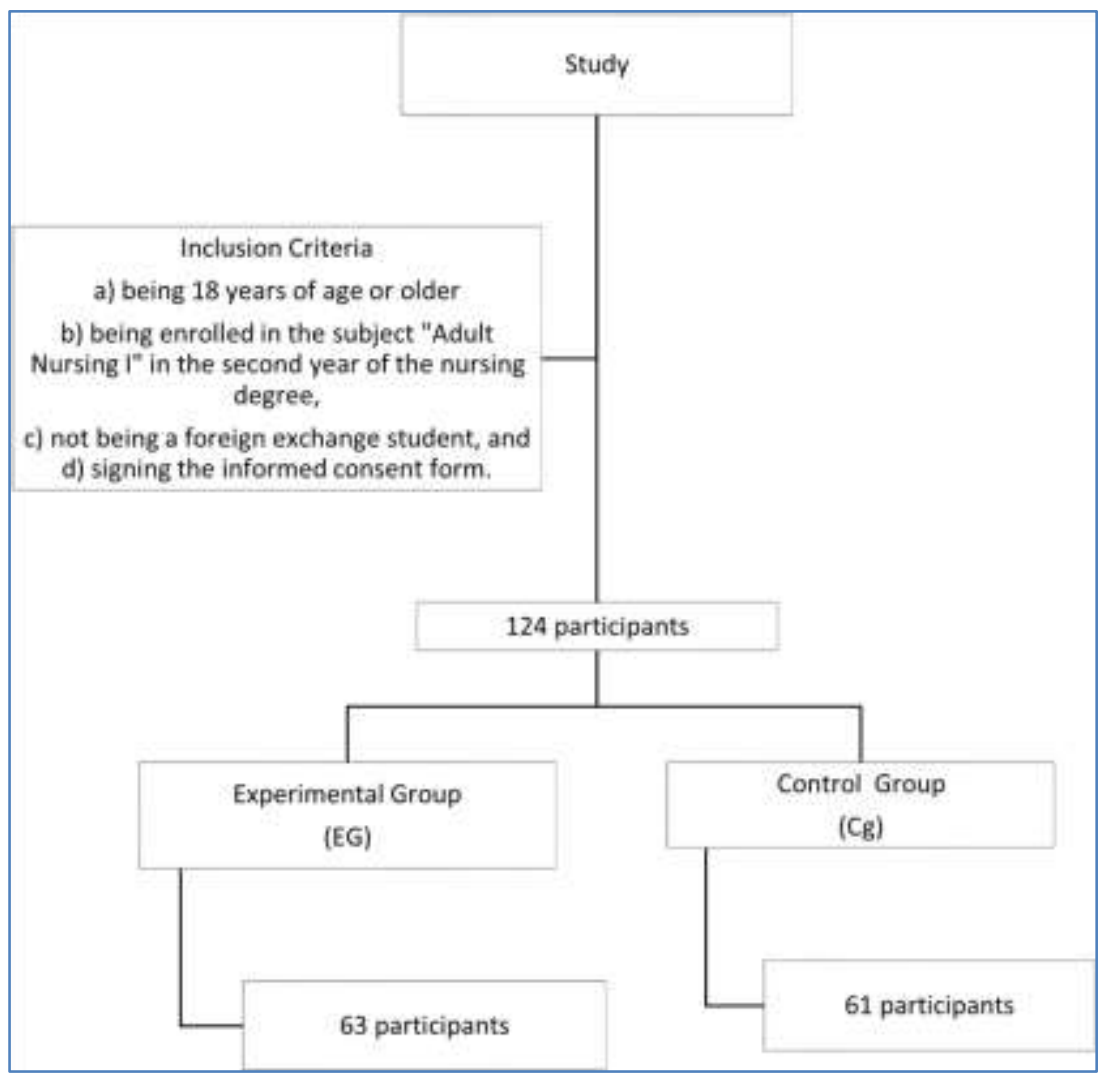

To evaluate students' attention during the showing of a video about inhalation therapy, 10 multiple-choice questions were created. These questions were centred on the content contained in the video.

\section{Ethical Considerations}

The study was approved by the university institutional review board ( $\left.{ }^{\circ} 8 / 2018\right)$. All of the study participants received information regarding its aim and signed informed consent documents for their participation.

\section{Data Collection}

First, permission was requested from the university institutional review board $\left(n^{\circ} 8 / 2018\right)$. The chief researcher informed the nursing students of the objective of the study, its voluntary nature, and the anonymous treatment of their data, as well as the possibility of leaving the study at any time. The students who decided to participate signed the informed consent forms. The CG put their cell phones on the table in front of them either in silent mode, with volume, vibration, or off, the way they normally had their phones in class. The EG left their cell phones, in sound or vibration mode, as they normally kept them, on a table located in the corner of the classroom. At the beginning of the class, both groups (CG and EG) filled out the NMP-Q questionnaire. 26 Then the participants proceeded to watch a video approximately 10 minutes in length about inhalation therapy. Once the video finished, the Knowledge test about the video was distributed. The EG, after this intervention, filled out the questionnaire on problematic cell phone use, whereas the CG took the questionnaire about 20 minutes before the class was over. Once all these questionnaires were filled out, they were deposited in a box located in one corner of the classroom, in order to guarantee the confidentiality and anonymity of the participants. Data collection took place between September and January 2019.

\section{Data Analysis}

For the data analysis, IBM SPSS Statistics version 23 (IBM, Armonk, NY) was used. First, a 
descriptive analysis was performed, and for the categorical variables, frequencies and percentages were calculated, while for the quantitative variables, measures of central tendency and dispersion were calculated. For the quantitative variables that had a normal distribution, the Student's $\mathrm{t}$ test was used. Finally, the nonparametric Mann-Whitney $U$ test and Spearman's correlation test were used. A value of $\mathrm{P}<$ .05 was considered significant.

\section{RESULTS}

Sociodemographic Characteristics of the Participants One hundred twenty-four participants took part in total, of which $79 \%(\mathrm{n}=98)$ were female, and $21 \%(\mathrm{n}=26)$ were male. The CG was made up of 61 participants $(49.2 \%)$, and the EG, 63 participants $(50.8 \%)$. The average age of the sample was $20.92 \pm$ 5.34 years. Regarding the age at which participants began using a cell phone, the average age was $13.13 \pm$ 3.30. The rest of the variables can be seen $P=.005$ ). In particular, the EG had an average score of based on the group they belong to in Table 1. 88.52 \pm 19.32 , and the CG, $78.52 \pm 19.35$ (in a range between 26 and 130 points), which indicates a greater perception of problematic cell phone use among those participants. Nomophobia and Problematic Cell Phone Use who were denied the use of their cell phones during the.

In regard to nomophobia, both groups showed higher video screening. Than-average levels at the beginning of the class. Specifically, the EG had an initial score of $95 \pm 21.60$, and the CG, $98.04 \pm 20.60$ (in a range between 20 and 140 points). No statistically significant differences were found between the regarding mindful awareness, statistically significant differ group in which participants were assigned and their ences were found between the EG and the CG (U $=1449.000 ;$ nomophobia scores $\left(\mathrm{t}_{122}=-0.804, \mathrm{P}=\right.$ $.817) . Z=-2.363, P=.018)$. More specifically, the EG indicated

On the other hand, regarding problematic cell phone an average score of $54.17 \pm 14.30$, and the $\mathrm{CG}$, $48.27 \pm 12.71$ use, statistically significant differences were found be- (range between 15 and 90 points), which shows that the EG tween the CG and the EG (U $=1355.500, \mathrm{Z}=-2.830$, was higher than average.

Table-1: Sociodemographic Characteristics of the Participants

\begin{tabular}{|c|c|c|c|c|}
\hline \multirow[t]{2}{*}{ Variable } & EG & & & CG \\
\hline & $\mathrm{n}$ & $\%$ & $\mathrm{n}$ & $\%$ \\
\hline \multicolumn{5}{|l|}{ Sex } \\
\hline Men & 11 & 17.5 & 15 & 24.6 \\
\hline Women & 52 & 82.5 & 46 & 75.4 \\
\hline Age & 21.08 (Mean) & $6.08(\mathrm{SD})$ & 20.75 (Mean) & $4.48(\mathrm{SD})$ \\
\hline Age of beginning of use of the mobile phone & 13.13 (Mean) & $3.53(\mathrm{SD})$ & 13.13 (Mean) & $3.07(\mathrm{SD})$ \\
\hline No. of times that you consult the mobile phone in class & 22.75 (Mean) & $24.15(\mathrm{SD})$ & 36.30 (Mean) & $32.45(\mathrm{SD})$ \\
\hline \multicolumn{5}{|l|}{ Time spent using the mobile phone per day } \\
\hline$<1 \mathrm{~h}$ & 2 & 3.2 & - & - \\
\hline $1-3 \mathrm{~h}$ & 10 & 15.9 & 14 & 23 \\
\hline $3-5 \mathrm{~h}$ & 23 & 36.5 & 12 & 19.7 \\
\hline$>5 \mathrm{~h}$ & 28 & 44.4 & 35 & 57.4 \\
\hline \multicolumn{5}{|l|}{ Use social networks } \\
\hline Yes & 56 & 88.9 & 57 & 88.5 \\
\hline No & 7 & 11.1 & 7 & 11.5 \\
\hline \multicolumn{5}{|l|}{ Use instant messaging } \\
\hline Yes & 62 & 98.4 & 58 & 95.1 \\
\hline No & 1 & 1.6 & 3 & 4.9 \\
\hline \multicolumn{5}{|l|}{ Search on the Internet } \\
\hline Yes & 26 & 41.3 & 31 & 51.7 \\
\hline No & 37 & 58.7 & 29 & 48.3 \\
\hline \multicolumn{5}{|l|}{ Phone calls } \\
\hline Yes & 18 & 28.6 & 22 & 36.1 \\
\hline No & 45 & 71.4 & 39 & 63.9 \\
\hline \multicolumn{5}{|l|}{ Listen to music } \\
\hline Yes & 29 & 46 & 32 & 52.5 \\
\hline No & 34 & 54 & 29 & 47.5 \\
\hline \multicolumn{5}{|l|}{ Watch videos } \\
\hline Yes & 26 & 41.3 & 26 & 42.6 \\
\hline No & 37 & 58.7 & 35 & 57.4 \\
\hline \multicolumn{5}{|l|}{ Games } \\
\hline Yes & 12 & 19 & 18 & 29.5 \\
\hline No & 51 & 81 & 43 & 70.5 \\
\hline
\end{tabular}

No statistically significant differences were found between CG and EG. 


\section{Knowledge Test}

Taking the final knowledge test into consideration, the EG obtained a higher average score $(9.83 \pm 3.25)$ than the CG $(7.11 \pm 2.96)$, finding statistically significant differences between them $(\mathrm{U}=$ 1859.500, $\mathrm{Z}=-2.151, \mathrm{P}=.015)$. A summarized version of the results of each scale can be found in Table 2 .

\section{Nomophobia, Problematic Cell Phone Use and the Mindful Attention Awareness Scale}

Lastly, a correlation was calculated between nomophobia, problematic cell phone usage, and the Mindful Attention Awareness Scale, distinguishing between the scores of each group, CG and EG. There were significant correlations found both in the $\mathrm{CG}$, as well as in the EG when comparing problematic use of cell phones with attention (Table 3 ).

\section{DISCUSSION}

The objective of this study was to find out the effects that problematic cell phone use and nomophobia have on attention and learning in nursing students. First, the participants showed high levels of nomophobia. These data coincide with data found in other studies [19-22].

Concerning problematic cell phone use, the participants in the EG had an increased perception of their own problematic cell phone use. The fact that they did not have access to their phones to satisfy their need for communication and information could be the reason $[1,2]$. It could also be due to the fear of missing out, which makes them want to be connected at all times to alleviate their social anxiety[31], since young people tend to use cell phones most based on their social interdependence, which is revealed on social media[32].

As far as the use of cell phones and attention, participants in the EG were shown to pay better attention during the class. This could be due to the fact that the students did not have access to their cell phones, which can reduce students' attention and distract them during class, due to the constant interruptions they cause [33]. Along the same lines, several studies report that the use of cell phones for multiple activities while in class diminishes students' attention [34,35]. Additionally, several different studies have shown that the use of cell phones during class leads to poor results in learning among students [24, 36]. On the other hand, several other studies have explored the impact of cell phone use on academic performance, finding that it has a negative effect $[35,37]$. Similarly, in one study carried out on university students, it was found that students who had their cell phones taken away during class obtained more knowledge without it[38]. These data coincide with the results of this study, in which participants in the EG got a higher score on the knowledge test.

On the other hand, there was a positive correlation found between problematic cell phone use and nomophobia in both groups. In this regard, there are various studies done on nursing students that have related nomophobia to problematic Internet use [19] and problematic cell phone use, given that the time spent on a cell phone has been associated with higher level of nomophobia as well[39].

Likewise, there were negative correlations found between nomophobia and/or problematic cell phone use and attention in both groups. Thus, the higher the level of nomophobia and/or problematic cell phone use, the less attention students pay. Similarly, several studies have shown that the level of nomophobia negatively interferes with students' attention [25, 38 ]. Particularly, Mendoza et al. [25] reported that the group that did not have a cell phone available to them paid less and less attention as the class went on, which may be due to the fact that individuals with nomophobia, when they do not have access to their cell phones, get increasingly anxious [5]. However, in this study, no statistically significant differences were found between the groups.

Taking into account all of the aforementioned data, it would be necessary to implement measures to regulate the use of cell phones in the academic environment, as well as in clinical practicums, and develop interventions in order to prevent and/or treat these human behaviour and cell phone interaction disorders.

The results of this study should be interpreted while keeping in mind a series of limitations. First, participants were selected as a convenience sample and only taken from one institution, which makes it difficult to generalize the results. On the other hand, the lack of previous research on this topic, and particularly on nursing students, complicates our ability to create a proper discussion of the topic, but, on the other hand, demonstrates the interesting, novel nature of this study. In addition, aiming to dig deeper into the results and repercussions of cell phone use on academic performance among nursing students, it would be necessary to do additional research that took other factors into account, such as learning and memory. Finally, several studies show that cell phone dependence interferes with interpersonal relationships and face-to-face communication [40, 41]; thus, it would be interesting to explore the effect of problematic cell phone use and/or nomophobia on communication with other professionals and with patients. 
Table-2: Mean and Standard Deviation of Each Scale Used

\begin{tabular}{|c|c|c|c|c|c|}
\hline \multirow{2}{*}{ Scale } & EG & & CG & \multirow{2}{*}{ P } \\
\cline { 2 - 5 } & Mean & SD & Mean & SD & \\
\hline Nomophobia & 95 & 21.60 & 98.04 & 20.60 & .817 \\
\hline Mobile Phone Problematic Use Scale & 88.52 & 19.32 & 78.52 & 19.35 & .005 \\
\hline Mindful Attention Awareness Scale & 54.17 & 14.30 & 48.27 & 12.71 & .018 \\
\hline Students' attention & 9.83 & 3.25 & 7.11 & 2.96 & .015 \\
\hline
\end{tabular}

Data in bold are statistically significant

Table-3: Correlation between Nomophobia, Mobile Phone Problematic Use Scale, and Mindful Attention Awareness Scale

\begin{tabular}{|c|c|c|c|c|c|}
\hline Group & Scales & & Nomophobia & $\begin{array}{c}\text { Mobile Phone Problematic } \\
\text { Use Scale }\end{array}$ & $\begin{array}{l}\text { Mindful Attention } \\
\text { Awareness }\end{array}$ \\
\hline \multirow[t]{6}{*}{ EG } & \multirow[t]{2}{*}{ Nomophobia } & $\mathrm{r}$ & 1.000 & 0.643 & -0.398 \\
\hline & & $\mathrm{P}$ & - & .000 & .001 \\
\hline & \multirow{2}{*}{$\begin{array}{l}\text { Mobile Phone Problematic } \\
\text { Use Scale }\end{array}$} & $\mathrm{r}$ & 0.643 & 1.000 & -0.602 \\
\hline & & $\mathrm{P}$ & .000 & - & .000 \\
\hline & \multirow{2}{*}{$\begin{array}{l}\text { Mindful Attention } \\
\text { Awareness }\end{array}$} & $\mathrm{r}$ & -0.398 & -0.602 & 1.000 \\
\hline & & $\mathrm{P}$ & .001 & .000 & - \\
\hline \multirow[t]{6}{*}{$\mathrm{CG}$} & \multirow[t]{2}{*}{ Nomophobia } & $\mathrm{r}$ & 1.000 & 0.711 & -0.512 \\
\hline & & $\mathrm{P}$ & - & .000 & .000 \\
\hline & \multirow{2}{*}{$\begin{array}{l}\text { Mobile Phone Problematic } \\
\text { Use Scale }\end{array}$} & $\mathrm{r}$ & 0.711 & 1.000 & -0.626 \\
\hline & & $\mathrm{P}$ & .000 & - & .000 \\
\hline & \multirow{2}{*}{$\begin{array}{l}\text { Mindful Attention } \\
\text { Awareness }\end{array}$} & $\mathrm{r}$ & -0.512 & -0.626 & 1.000 \\
\hline & & $\mathrm{P}$ & .000 & .000 & - \\
\hline
\end{tabular}

\section{CONCLUSION}

It is a common occurrence to see cell phones used by nursing students in class. A relationship has been found between nomophobia and problematic cell phone use. The students who do not have access to their cell phones during class perceive more problematic cell phone usage and also pay closer attention during class. Because of this, it is important to create policies and norms restricting cell phone use during all types of academic training among nursing students, as well as creating best practice guides for appropriate use of such devices.

\section{REFERENCES}

1. Mosa, A. S. M., Yoo, I., \& Sheets, L. (2012). A systematic review of healthcare applications for smartphones. BMC medical informatics and decision making, 12(1), 67.

2. Billieux, J., Maurage, P., Lopez-Fernandez, O., Kuss, D. J., \& Griffiths, M. D. (2015). Can disordered mobile phone use be considered a behavioral addiction? An update on current evidence and a comprehensive model for future research. Current Addiction Reports, 2(2), 156-162.

3. Konok, V., Pogány, Á., \& Miklósi, Á. (2017). Mobile attachment: Separation from the mobile phone induces physiological and behavioural stress and attentional bias to separation-related stimuli. Computers in Human Behavior, 71, 228239.

4. Oulasvirta, A., Rattenbury, T., Ma, L., \& Raita, E. (2012). Habits make smartphone use more pervasive. Personal and

Computing, 16(1), 105-114.

5. Elhai, J. D., Dvorak, R. D., Levine, J. C., \& Hall, B. J. (2017). Problematic smartphone use: A conceptual overview and systematic review of relations with anxiety and depression psychopathology. Journal of affective disorders, 207, 251-259.

6. Han, S., Kim, K. J., \& Kim, J. H. (2017). Understanding nomophobia: Structural equation modeling and semantic network analysis of smartphone separation anxiety. Cyberpsychology, Behavior, and Social Networking, 20(7), 419-427.

7. Yildirim, C., \& Correia, A. P. (2015). Exploring the dimensions of nomophobia: Development and validation of a self-reported questionnaire. Computers in Human Behavior, 49, 130-137.

8. Tams, S., Legoux, R., \& Léger, P. M. (2018). Smartphone withdrawal creates stress: A moderated mediation model of nomophobia, social threat, and phone withdrawal context. Computers in Human Behavior, 81, 1-9.

9. Hartanto, A., \& Yang, H. (2016). Is the smartphone a smart choice? The effect of smartphone separation on executive functions. Computers in Human Behavior, 64, 329-336.

10. Garrett, B., \& Klein, G. (2008). Value of wireless personal digital assistants for practice: perceptions of advanced practice nurses. Journal of Clinical Nursing, 17(16), 2146-2154.

11. George, L. E., Davidson, L. J., Serapiglia, C. P., Barla, S., \& Thotakura, A. (2010). Technology in 
nursing education: a study of PDA use by students. Journal of Professional Nursing, 26(6), 371-376.

12. O'Connor, S., \& Andrews, T. (2015). Mobile technology and its use in clinical nursing education: a literature review. Journal of Nursing Education, 54(3), 137-144.

13. O'Connor, S., \& Andrews, T. (2018). Smartphones and mobile applications (apps) in clinical nursing education: a student perspective. Nurse education today, 69, 172-178.

14. Raman, J. (2015). Mobile technology in nursing education: where do we go from here? A review of the literature. Nurse education today, 35(5), 663672.

15.Patterson, B. J., Secco, L. M., Doiron-Maillet, N., Amirault, D., \& Furlong, K. (2013). Evaluation of Nursing Central as an information tool, part I: student learning. Nursing education perspectives, 34(6), 416-418.

16. Kim, M. S., Park, J. H., \& Park, K. Y. (2012). Development and effectiveness of a drug dosage calculation training program using cognitive loading theory based on smartphone application. Journal of Korean Academy of Nursing, 42(5), 689-698.

17. Johansson, P. E., Petersson, G. I., \& Nilsson, G. C. (2013). Nursing students' experience of using a personal digital assistant (PDA) in clinical practice-an intervention study. Nurse education today, 33(10), 1246-1251.

18. Strandell-Laine, C., Stolt, M., Leino-Kilpi, H., \& Saarikoski, M. (2015). Use of mobile devices in nursing student-nurse teacher cooperation during the clinical practicum: An integrative review. Nurse education today, 35(3), 493-499.

19. Ayar, D., Gerçeker, G. Ö., Özdemir, E. Z., \& Bektas, M. (2018). The effect of problematic internet use, social appearance anxiety, and social media use on nursing students' nomophobia levels. CIN: Computers, Informatics, Nursing, 36(12), 589-595.

20.Gutiérrez-Puertas, L., Márquez-Hernández, V. V., São-Romão-Preto, L., Granados-Gámez, G., Gutiérrez-Puertas, V., \& Aguilera-Manrique, G. (2019). Comparative study of nomophobia among Spanish and Portuguese nursing students. Nurse education in practice, 34, 79-84.

21. Cho, S., \& Lee, E. (2016). Distraction by smartphone use during clinical practice and opinions about smartphone restriction policies: A crosssectional descriptive study of nursing students. Nurse education today, 40, 128-133.

22. Aguilera-Manrique, G., Márquez-Hernández, V. V., Alcaraz-Córdoba, T., Granados-Gámez, G., Gutiérrez-Puertas, V., \& Gutiérrez-Puertas, L. (2018). The relationship between nomophobia and the distraction associated with smartphone use among nursing students in their clinical practicum. PloS one, 13(8), e0202953.
23. Hawi, N. S., \& Samaha, M. (2016). To excel or not to excel: Strong evidence on the adverse effect of smartphone addiction on academic performance. Computers \& Education, 98, 81-89.

24.Lepp, A., Barkley, J. E., \& Karpinski, A. C. (2014). The relationship between cell phone use, academic performance, anxiety, and satisfaction with life in college students. Computers in human behavior, 31, 343-350.

25. Mendoza, J. S., Pody, B. C., Lee, S., Kim, M., \& McDonough, I. M. (2018). The effect of cellphones on attention and learning: The influences of time, distraction, and nomophobia. Computers in Human Behavior, 86, 52-60.

26. Gutiérrez-Puertas, L., Márquez-Hernández, V. V., \& Aguilera-Manrique, G. (2016). Adaptation and validation of the Spanish version of the nomophobia questionnaire in nursing studies. CIN: Computers, Informatics, Nursing, 34(10), 470-475.

27. Bianchi, A., \& Phillips, J. G. (2005). Psychological predictors of problem mobile phone use. CyberPsychology \& Behavior, 8(1), 39-51.

28. de-Sola, J., Talledo, H., Rodríguez de Fonseca, F., \& Rubio, G. (2017). Prevalence of problematic cell phone use in an adult population in Spain as assessed by the Mobile Phone Problem Use Scale (MPPUS). PLoS One, 12(8), e0181184.

29. Brown, K. W., \& Ryan, R. M. (2003). The benefits of being present: mindfulness and its role in psychological well-being. Journal of personality and social psychology, 84(4), 822.

30. Soler Ribaudi, J., Tejedor, R., Feliu-Soler, A., Pascual Segovia, J. C., Cebolla i Martí, A. J., Soriano, J., \& Pérez, V. (2012). Propiedades psicométricas de la versión española de la escala Mindful Attention Awareness Scale (MAAS).

31.Przybylski, A. K., Murayama, K., DeHaan, C. R., \& Gladwell, V. (2013). Motivational, emotional, and behavioral correlates of fear of missing out. Computers in Human Behavior, 29(4), 18411848.

32. Salehan, M., \& Negahban, A. (2013). Social networking on smartphones: When mobile phones become addictive. Computers in human behavior, 29(6), 2632-2639.

33. Taneja, A., Fiore, V., \& Fischer, B. (2015). Cyberslacking in the classroom: Potential for digital distraction in the new age. Computers \& Education, 82, 141-151.

34. Kuznekoff, J. H., \& Titsworth, S. (2013). The impact of mobile phone usage on student learning. Communication Education, 62(3), 233252.

35.Lau, W. W. (2017). Effects of social media usage and social media multitasking on the academic performance of university students. Computers in human behavior, 68, 286-291.

36.Lepp, A., Barkley, J. E., \& Karpinski, A. C. (2015). The relationship between cell phone use and 
academic performance in a sample of US college students. Sage Open, 5(1), 2158244015573169.

37. Cheever, N. A., Rosen, L. D., Carrier, L. M., \& Chavez, A. (2014). Out of sight is not out of mind: The impact of restricting wireless mobile device use on anxiety levels among low, moderate and high users. Computers in Human Behavior, 37, 290-297.

38.Lee, S., Kim, M. W., McDonough, I. M., Mendoza, J. S., \& Kim, M. S. (2017). The Effects of Cell Phone Use and Emotion- regulation Style on College Students' Learning. Applied Cognitive Psychology, 31(3), 360-366.

39. Kaur, A., \& Sharma, P. (2015). A descriptive study to assess the risk of developing nomophobia among students of selected nursing colleges Ludhiana, Punjab. International Journal of Psychiatric Nursing, 1(2), 1-6.

40.Chiu, S. I. (2014). The relationship between life stress and smartphone addiction on Taiwanese university student: A mediation model of learning self-efficacy and social self-efficacy. Computers in human behavior, 34, 49-57.

41. Chotpitayasunondh, V., \& Douglas, K. M. (2016). How "phubbing" becomes the norm: The antecedents and consequences of snubbing via smartphone. Computers in Human Behavior, 63, 918. 